\title{
Melting the tip of the iceberg: bronchoscopic-guided transbronchial microwave ablation
}

\author{
Michael A. Pritchett ${ }^{1}$, Charles C. Schirmer ${ }^{2}$, Paul Laeseke ${ }^{3}$ \\ ${ }^{1}$ Department of Pulmonary Medicine, FirstHealth of the Carolinas \& Pinehurst Medical Clinic, Pinehurst, NC, USA; ${ }^{2}$ Department of Pathology, \\ FirstHealth of the Carolinas, Pinehurst, NC, USA; ${ }^{3}$ Department of Radiology, University of Wisconsin, Madison, WI, USA \\ Correspondence to: Michael A. Pritchett, DO, MPH. Department of Pulmonary Medicine, FirstHealth of the Carolinas \& Pinehurst Medical Clinic, \\ 205 Page Rd. Pinehurst, NC 28374, USA. Email: mpritchett@pinehurstmedical.com. \\ Provenance and Peer Review: This article was commissioned by the editorial office, Translational Lung Cancer Research. The article did not undergo \\ external peer review. \\ Comment on: Yuan HB, Wang XY, Sun JY, et al. Flexible bronchoscopy-guided microwave ablation in peripheral porcine lung: a new minimally- \\ invasive ablation. Transl Lung Cancer Res 2019;8:787-96.
}

Submitted Mar 29, 2020. Accepted for publication Apr 22, 2020.

doi: $10.21037 /$ tlcr.2020.04.09

View this article at: http://dx.doi.org/10.21037/tlcr.2020.04.09

Percutaneous CT-guided thermal ablation is an increasingly used therapy for patients with either unresectable early stage non-small cell lung cancer or oligometastatic disease. To date, radiofrequency (RF) energy has been the most widely used ablative modality for lung ablation (1). However, microwaves (MW) offer a number of theoretical advantages when compared with RF, including less susceptibility to heat sinks, faster heating to higher temperatures, larger ablation zones, and the ability to penetrate high impedance tissues (i.e., aerated lung tissue) (2). For these reasons, there has been greater adoption of MW for treating lung tumors in recent years.

While percutaneous MW ablation (MWA) is a safe and effective procedure, the majority of complications that do occur are pleural-related and result from the transthoracic and transpleural puncture (3). Reported rates of pneumothorax during CT-guided lung ablation vary widely but are as high as $63 \%$ with up to $19 \%$ requiring placement of a chest tube (4-6). Placement of a chest tube increases procedure-related morbidity, prolongs the length of the hospital stay and increases the cost of the ablation procedure, particularly if the patient develops a persistent bronchopleural fistula necessitating prolonged pleural drainage (up to $2 \%$ of cases) $(7,8)$. Additional complications related to the transthoracic puncture during percutaneous ablation include pleural effusion (6-19\% of cases), hemothorax, empyema, pain, skin burns and tract seeding (9-15).
A bronchoscopic or airway-based approach to accessing tumors is associated with a lower complication rate when compared with a transthoracic approach. For example, recent meta-analyses report the rates of pneumothorax after bronchoscopic and transthoracic biopsy as $1.5 \%$ and $18.8-25.3 \%$, respectively $(16,17)$. Experience with transbronchial ablation of lung tumors is extremely limited. Bronchoscopy-guided RF ablation of lung tumors has been described $(18,19)$. Early reports demonstrate it to be feasible and safe with no major adverse events reported. Unfortunately, local tumor progression rates have been unacceptably high (up to 50\%) (18). Transbronchial MWA (tMWA) was described as early as 2013 (20) and multiple commercial systems have recently been developed and are in the early phases of clinical trials (21). By combining the lower complication rate associated with a transbronchial approach with more efficient heating of lung tissue with MW, tMWA promises to provide a safe and highly effective, minimally invasive treatment option for early stage lung cancer and oligometastatic disease. When combined with transbronchial biopsy, endobronchial ultrasound (EBUS) guided lymph node staging, and rapid on-site pathologic examination (ROSE), tMWA may facilitate diagnosis, staging and treatment of early stage lung cancer in a single, safe, minimally invasive procedure (22).

In a recent issue of this journal, Yuan and colleagues used flexible bronchoscopy to navigate to peripheral targets in 
a porcine model to perform bronchoscopy-guided watercooled MWA (23). This was compared to an ex vivo model of ablation in uninflated porcine lungs. Computed tomography (CT) was performed periprocedurally and at 24 hours, 2 weeks and 4 weeks post ablation. In addition, ablation zones were excised at 24 hours and 4 weeks post-ablation for pathological evaluation. No complications were encountered and, based on temperature, imaging and pathologic data, the authors concluded that flexible bronchoscopy-guided watercooled MWA is feasible and safe.

In the ex vivo model with their ablation catheter placed via direct puncture of uninflated lungs, they achieved a temperature of $60{ }^{\circ} \mathrm{C}$ (temperature at which near instantaneous cell death and necrosis occurs) $2 \mathrm{~cm}$ from the antenna implying this would equate to an approximately $4 \mathrm{~cm}$ ablation zone. These temperatures were only achieved using power settings of 80 and 90 watts with treatment times of 4.8 and $3.6 \mathrm{~min}$, respectively.

In studies 2 and 3 ( 6 ex vivo and 12 in vivo, all mechanically ventilated) the ablation zone was measured by pathologic dissection along the axis of the bronchus where the antenna was inserted. This revealed average ablation zone dimensions (length $\times$ diameter) of $22.7 \mathrm{~mm} \times 15 \mathrm{~mm}$ in ex vivo models and $19.3 \mathrm{~mm} \times 13.2 \mathrm{~mm}$ in the in vivo model at 24 hours. A small group in the in vivo arm were sacrificed at 4 weeks post-ablation and the dimensions of the zone of treatment at that time was $6.8 \mathrm{~mm} \times 4.7 \mathrm{~mm}$.

The histopathologic assessment revealed some interesting findings. At 24 hours post-ablation, the bronchial cartilage was retained in all cases and was still viable without any apoptosis. There was a clear zone of coagulative necrosis representing ablated tissue that was "almost completely apoptotic". This area is surrounded by a rim of congestion and hemorrhage at the interface of the necrotic and viable tissue, similar to what has been previously described (24). At 4 weeks post-ablation, there is reconstitution of the mucosa with collapse of the necrotic tissue and replacement by a fibrous scar in a circular pattern around the bronchus. The authors suggest the bronchial mucosa and cartilage remained intact however it is possible that there was reformation of the mucosa. We agree that the cartilage appears relatively protected and this probably served as a scaffold for mucosal repair. Additionally, the porcine lung is more cartilaginous in structure compared to human lungs (25) and this may have an effect on the ability to extrapolate some of this data to human subjects.

There are some notable limitations to the study. As the authors note, the study was performed in normal, non-tumor-bearing ex vivo and in vivo porcine lungs. While this is an important limitation, large animal tumor models are lacking, and the porcine model is commonly and appropriately used for these types of studies. No complications were encountered in this study, but the small number of animals limits a true assessment of the safety profile, particularly for adverse events that occur with relatively low frequency. Finally, and perhaps most importantly, the sizes of the ablation zones were relatively small. The ablation zones were comparable in size to those previously described for bronchoscopic RF ablation and smaller than those reported with percutaneous and other tMWA systems $(2,19,20)$. Differences in antenna design, cooling mechanism (e.g., carbon dioxide $v s$. water cooling), ablation settings (input power and time), and measurement technique may explain the smaller size. Also, the thicker cartilage in a porcine model may decrease the penetration of the ablation zone into the lung tissue compared with human lung (25). The thicker cartilage and uninflated lung may explain the difference in size of the adequate treatment zone in study 1 (20 $\mathrm{mm}$ in the non-transbronchial ex vivo lungs) compared to studies 2 and 3 (transbronchial models).

Regardless, given that the goal during any ablation is to achieve complete coverage of the tumor as well as a circumferential ablative margin of at least $5-10 \mathrm{~mm}$, it is clear that larger ablation zones are desired. Otherwise, the procedures will be more complex and time consuming as multiple sequential overlapping ablations will be needed for all but the smallest tumors. The authors propose inducing "artificial atelectasis" via bronchial blockade to reduce ventilation associated cooling. However, this may be counterproductive as it will limit visibility of both the target tumor and resultant ablation zone.

In our personal experience with bronchoscopic-guided tMWA we have seen more robust ablation zones compared to what is described in this study. As noted above, this may be related to differences in system design (e.g., $\mathrm{CO}_{2}$-cooled $v s$. water-cooled). Additionally, our ablation targets are typically in more peripheral locations while the transbronchial ablations of the porcine model in this study, involved cartilaginous bronchi and surrounding parenchyma. Although our experience has not involved subsequent resection for histologic evaluation, we were able to visualize the zone of ablation with intra- and postprocedural cone-beam CT (CBCT). The use of CBCT was also invaluable to ensure accurate placement of the ablation catheter with respect to the lesion. We consider the use of CBCT compulsory for tMWA in human subjects. 
Despite the aforementioned limitations, the authors should be commended for their contribution to the growing literature on this topic. There is currently significant interest in tMWA by advanced bronchoscopists, interventional pulmonologists and thoracic surgeons. There are currently multiple vendors creating RF and MW catheters for transbronchial ablation. All of these products are currently under study in formal clinical trials. This study is yet another step forward and serves to help melt the tip of the iceberg that is tMWA.

\section{Acknowledgments}

Funding: None.

\section{Footnote}

Conflicts of Interest: All authors have completed the ICMJE uniform disclosure form (available at http://dx.doi. org/10.21037/tlcr.2020.04.09). MAP reports personal fees from Medtronic, personal fees from BodyVision, personal fees from Intuitive Surgical, personal fees from Philips, personal fees from Biodesix, personal fees from AstraZeneca, personal fees from Johnson \& Johnson, personal fees from United Therapeutics, personal fees from Actelion, other from Inivata, personal fees from Pfizer, personal fees from Ambu, personal fees from Boston Scientific, outside the submitted work; and Wife is an employee of Medtronic; PL reports personal fees from NeuWave Medical/Ethicon, other from HistoSonics, other from Elucent Medical, other from McGinley Orthopedic Innovations, grants from Siemens Medical, outside the submitted work; In addition, PL has a patent Energy delivery systems and uses thereof issued to NeuWave Medical. CCS has no conflicts of interest to declare.

Ethical Statement: The authors are accountable for all aspects of the work in ensuring that questions related to the accuracy or integrity of any part of the work are appropriately investigated and resolved.

Open Access Statement: This is an Open Access article distributed in accordance with the Creative Commons Attribution-NonCommercial-NoDerivs 4.0 International License (CC BY-NC-ND 4.0), which permits the noncommercial replication and distribution of the article with the strict proviso that no changes or edits are made and the original work is properly cited (including links to both the formal publication through the relevant DOI and the license). See: https://creativecommons.org/licenses/by-nc-nd/4.0/.

\section{References}

1. de Baere T, Tselikas L, Catena V, et al. Percutaneous thermal ablation of primary lung cancer. Diagn Interv Imaging 2016;97:1019-24.

2. Brace CL, Hinshaw JL, Laeseke PF, et al. Pulmonary thermal ablation: comparison of radiofrequency and microwave devices by using gross pathologic and CT findings in a swine model. Radiology 2009;251:705-11.

3. Vogl TJ, Eckert R, Naguib NN, et al. Thermal Ablation of Colorectal Lung Metastases: Retrospective Comparison Among Laser-Induced Thermotherapy, Radiofrequency Ablation, and Microwave Ablation. AJR Am J Roentgenol 2016;207:1340-9.

4. Egashira Y, Singh S, Bandula S, et al. Percutaneous High-Energy Microwave Ablation for the Treatment of Pulmonary Tumors: A Retrospective Single-Center Experience. J Vasc Interv Radiol 2016;27:474-9.

5. Healey TT, March BT, Baird G, et al. Microwave Ablation for Lung Neoplasms: A Retrospective Analysis of LongTerm Results. J Vasc Interv Radiol 2017;28:206-11.

6. Liu H, Steinke K. High-powered percutaneous microwave ablation of stage I medically inoperable non-small cell lung cancer: a preliminary study. J Med Imaging Radiat Oncol 2013;57:466-74.

7. Sakurai J, Hiraki T, Mukai T, et al. Intractable pneumothorax due to bronchopleural fistula after radiofrequency ablation of lung tumors. J Vasc Interv Radiol 2007;18:141-5.

8. Zheng A, Wang X, Yang X, et al. Major complications after lung microwave ablation: a single-center experience on 204 sessions. Ann Thorac Surg 2014;98:243-8.

9. Chua TC, Sarkar A, Saxena A, et al. Long-term outcome of image-guided percutaneous radiofrequency ablation of lung metastases: an open-labeled prospective trial of 148 patients. Ann Oncol 2010;21:2017-22.

10. Hiraki T, Tajiri N, Mimura H, et al. Pneumothorax, pleural effusion, and chest tube placement after radiofrequency ablation of lung tumors: incidence and risk factors. Radiology 2006;241:275-83.

11. Hiraki T, Mimura H, Gobara H, et al. Two cases of needle-tract seeding after percutaneous radiofrequency ablation for lung cancer. J Vasc Interv Radiol 2009;20:415-8.

12. Nomura M, Yamakado K, Nomoto Y, et al. Complications 
after lung radiofrequency ablation: risk factors for lung inflammation. Br J Radiol 2008;81:244-9.

13. Okuma T, Matsuoka T, Yamamoto A, et al. Frequency and risk factors of various complications after computed tomography-guided radiofrequency ablation of lung tumors. Cardiovasc Intervent Radiol 2008;31:122-30.

14. Sano Y, Kanazawa S, Gobara H, et al. Feasibility of percutaneous radiofrequency ablation for intrathoracic malignancies: a large single-center experience. Cancer 2007;109:1397-405.

15. Yamakado K, Akeboshi M, Nakatsuka A, et al. Tumor seeding following lung radiofrequency ablation: a case report. Cardiovasc Intervent Radiol 2005;28:530-2.

16. Heerink WJ, de Bock GH, de Jonge GJ, et al. Complication rates of CT-guided transthoracic lung biopsy: meta-analysis. Eur Radiol 2017;27:138-48.

17. Wang Memoli JS, Nietert PJ, et al. Meta-analysis of guided bronchoscopy for the evaluation of the pulmonary nodule. Chest 2012;142:385-93.

18. Koizumi T, Tsushima K, Tanabe T, et al. BronchoscopyGuided Cooled Radiofrequency Ablation as a Novel Intervention Therapy for Peripheral Lung Cancer. Respiration 2015;90:47-55.

19. Safi S, Op den Winkel J, Kramer S, et al. A new

Cite this article as: Pritchett MA, Schirmer CC, Laeseke P. Melting the tip of the iceberg: bronchoscopic-guided transbronchial microwave ablation. Transl Lung Cancer Res 2020;9(4):960-963. doi: 10.21037/tlcr.2020.04.09 bronchoscopic catheter for the transbronchial ablation of pulmonary nodules. Lung Cancer 2018;124:125-9.

20. Ferguson J, Egressy K, Schefelker R, et al. Bronchoscopically-Guided Microwave Ablation in the Lung. Chest 2013;144:87A.

21. Lau K, Spiers A, Pritchett M, et al. P1.05-06 Bronchoscopic Image-Guided Microwave Ablation of Peripheral Lung Tumours - Early Results. J Thorac Oncol 2018;13:S542.

22. Drevets P, Chung JM, Schampaert S, et al. Hybrid Operating Room: One-Stop-Shop for Diagnosis, Staging, and Treatment Innovations (Phila) 2019;14:463-7.

23. Yuan HB, Wang XY, Sun JY, et al. Flexible bronchoscopyguided microwave ablation in peripheral porcine lung: a new minimally-invasive ablation. Transl Lung Cancer Res 2019;8:787-96.

24. Durick NA, Laeseke PF, Broderick LS, et al. Microwave Ablation with Triaxial Antennas Tuned for Lung: Results in an in Vivo Porcine Model. Radiology 2008;247:80-7.

25. Judge EP, Hughes JML, Egan JJ, et al. Anatomy and bronchoscopy of the porcine lung. A model for translational respiratory medicine. Am J Respir Cell Mol Biol 2014;51:334-43. 